\title{
Indonesia Football Philosophy (Filanesia)
}

\author{
Emral $^{1 *}$, Danurwindo $^{2}$, Ganesha $^{2}$ \\ ${ }^{1}$ Faculty of Sport Science, Universitas Negeri Padang, Prof. Dr. Hamka, Padang, Indonesia \\ ${ }^{2}$ Persatuan Sepakbola Seluruh Indonesia \\ *Corresponding author. Email: $\underline{\text { abus@yahoo.co.id }}$
}

\begin{abstract}
This stage of coaching will score players who love football games, have skillful football action skills, and competence in the game. Everything can be a guide for young trainers on how to organize good and right practice. Also, a guide to providing training materials that are suitable and appropriate to the age and level of the players being trained. The hope, the quality standard of soccer training in this country will increase sharply. So as to create quality future players who will bring the national team to victory at the world level. Filanesia and this curriculum will not be socialized and realized without the help of experts. The experts referred to here are trainers who already have certificates using the Filanesia curriculum. PSSI has held many coach courses since 2016 until now 43 times the C AFC licensing course 5 times B AFC and 2 times A AFC and 1 time Pro License, but this curriculum can only be run mid 2017 (HPU PSSI, 2018). Besides that this curriculum is needed to be disseminated to FIK Soccer teaching staff throughout Indonesia. Not just socialization, but the Coaching Department must cooperate with PSSI to run this curriculum by entering Filanesia into the training football curriculum. Finally, students who graduate training automatically obtain an AFC-level certificate.
\end{abstract}

\section{Keywords: Philosophy and Indonesian Football}

\section{INTRODUCTION}

There are still a few coaches who can answer what the philosophy of Indonesian football is. This has happened so far, we only use the AFC curriculum until 2017. Mid 2017 The Indonesian Football Philosophy Book is ready to socialize to prospective D National license participants, AFC C and AFC B as well as the AFC licensing course. Based on data from HPU PSSI The number of courses conducted is as follows:

\section{DISCUSSION}

\subsection{What Is Indonesian Football Philosophy?}

In this section of the book, objective facts have been explained in football This fact is determined by the FIFA Laws of The Game. Where FIFA game rules make football a universal game [4]. Another fact that football must be won with more goals scored than conceding is something that is undeniable. That is what then football recognizes moments of attack, defense and transition. In the objective framework to achieve victory with more goals scored than conceded [1]. A subjective choice about how to attack, survive and transition. Well, the Indonesian Football Philosophy is a formula for how to play chosen by Indonesia to reach the highest level of football achievement [2].

As we can see the success of fostering young to senior age in FFA Australia thanks to their clear and detailed football curriculum regarding coach education [3].
Of course the way to play chosen to be able to bring our football to a higher level must consider several key things. First, the geographical-cultural and sociological conditions of the Indonesian people. Indonesia's geographical conditions which are located on the equator make our country tropical. For this reason, we need to play a way that is developed according to these conditions. Then in a cultural and sociological way, the Indonesian people highly uphold the hierarchy. The existence of exemplary role models and patrons in the soccer team is very important. In addition, our society also highly values togetherness values. A reflection on the importance of a way of playing oriented to teamwork.

The next consideration is the excess strength of Indonesian players. With average posture, our players are endowed with high speed and agility. Players have the advantage of short sprints. In football action, this advantage is manifested in the superiority of Indonesian players when carrying out $1 \mathrm{v} 1$ solo attacks. The final consideration is the demands of top level football. Modern football trends require proactive games when defending and attacking. Proactive means the desire of the team to dominate possession and create opportunities when attacking. Also proactive in pressing when defending to be able to regain control of the ball. In addition, the transition between the two moments is a magical moment that determines the occurrence of goals [2]. 


\subsection{Proactive Football}

as a Choice In football, there are many ways to play for success. Some teams chose to make solid defense the starting point of the game. They let opponents master the ball, while waiting for the opportunity to grab the ball. Defense and pressing forces the opponent wrong and the team can win the ball. After grabbing the ball, the team can launch a fast counter attack. This style is often called Reactive Play. Many other teams chose to make possession of the ball the basis of how to play it. The team proactively continues to control the ball to find ways to progress the ball forward with the main goal creating goal opportunities. When losing the ball, the team proactively presses for as fast as possible to get back and control the ball. This style approach is called Proactive Play. Seeing the success of top level teams in the World Cup, European Cup and European Champions League in the past decade shows the trend of modern football leading to proactive football. Barcelona, Real Madrid, FC Bayern and the German national team are the images of a team that has successfully played proactive football. Always proactively dominating possession to create goal opportunities. Also proactive to do pressing to seize the ball [4].

The proactive football model is also suitable to see the advantages of Indonesian players who have speed and agility. The superiority of the $1 \mathrm{v} 1$ solo attack game will complement the level of effectiveness of this proactive football. Culturally, proactive football also fits with the aggressiveness of Indonesian players [2].

\subsection{Goal Oriented Possession}

In proactive football there are two approaches to ball possession that can be done. That is, direct play forward (direct play) ala Roger Schmidt or Tony Pulis. Also constructive play from the back, line to line to the front (constructive play) like Pep Guardiola or Thomas Tuchel. From statistical data in general in some big world level competitions, direct play games, 2-3 passing forward and hope that the second ball of aerial duels ends mostly in teams losing the ball. Constructive games from line to line with more passing proved to be more effective in creating scoring opportunities.

\subsection{Direct Play Constructive Play}

pressing your opponent by sending the ball directly to the striker as fast as possible. - dominate the game by fighting air ball duel and physical contact to score goals. long ball games and the fight for the second ball to unload the opponent's defense - movements, combination games, solo play to dismantle the opponent's defense. - based on these considerations, indonesia chose constructive possession based games from line to line. in addition to a very positive constructive possession in creating goal opportunities, this model is also useful for developing the skills of individual young players.

By playing constructively from line to line, the attack route will involve more players. The flow of the ball will flow from the goalkeeper, to the defender, midfielder to forward. Compare this with direct play-based possession games that tend to jump over the midfield. Where games often only involve goalkeepers or defenders with strikers.

Need to understand ball mastery is not a goal, but a tool. The purpose of possession is to create a goal scoring opportunity. For this reason, despite relying on constructive-based possession from line to line, attack orientation must be progressive in the future, leading to the opponent's goal. So that attack progress with passing or dribbling in the future must be the highest priority if possible [2].

If the team loses the ball, the style of the negative transition chosen is as soon as possible to immediately press at the location where the ball is lost (immediate pressing). Priority for direct pressing is done with the aim that the team can reclaim the ball as soon as possible. If immediate pressing cannot be done, the team must reorganize to enter the Press Build Up phase.

Indonesian Football Philosophy in ATTACK: "Attack PROACTIVELY with CONSTRUCTIVE ball possession from line to PROGRESSIVE oriented line forward to score goals."

\subsection{Smart Zonal Pressing}

The proactive soccer approach gives more preference to ball possession. Where when our team controls the ball, the opponent will automatically not be able to score. For this reason a proactive approach must also be made when the team survives. That is by pressing orientation for as fast as possible to grab the ball. So that it can regain control of the ball. Pressing orientation to get the ball as fast as possible do not misinterpret it as a high pressing throughout the game. The height of the team pressing line is very dependent on the situation. In many situations, the team can capture the ball faster with a moderate or even low pressing line. In this case the team intelligence is needed to collectively read the game situation. Then determine the height of the pressing line to be able to seize the ball as fast as possible. The team must understand which situation must be responded to with high pressing line. But also other situations that must be responded to with a low or medium pressing line. When doing pressing, guarding is done by a team not based on people (man to man marking). Instead the team collectively presses on a zonal marking basis. All players together must take care of space by minimizing the opponent's space (make the small pitch and squeeze the space). Where the guarded space is oriented to the location of the ball. Smart Zonal Pressing!

Immediately after grabbing the ball, the first priority is to do a quick counter attack. This is done by exploiting the space in front of and behind the opposing defender's line. If a quick counter cannot be done, then the team must return to Build Up. Indonesian Football Philosophy in Defense "Defend PROACTIVE by conducting SITUATIONAL PRESSING based on ZONAL guarding (HPU, 2017: 18).

\section{CONCLUSION}

Based on the above description, the Indonesian Football Association must choose subjectively about how 
to attack, survive and transition in playing football called Philosophy. Thus, the Indonesian Football Philosophy is a formula for how to play chosen by Indonesia to reach the highest level of football achievement.

Based on these considerations, Indonesia chose constructive possession based games from line to line. In addition to a very positive constructive possession in creating goal opportunities, this model is also useful for developing the skills of individual young players. By playing constructively from line to line, the attack route will involve more players. The flow of the ball will flow from the goalkeeper, to the defender, midfielder to forward. Compare this with direct play-based possession games that tend to jump over the midfield. Where games often only involve goalkeepers or defenders with strikers.

Indonesian Football Philosophy in ATTACK: "Attack PROACTIVELY with CONSTRUCTIVE ball possession from line to PROGRESSIVE oriented line forward to score goals."

Indonesian Football Philosophy in Defense "Defend PROACTIVELY by doing SITUATIONAL PRESSING based on ZONAL guarding.".

\section{REFERENCES}

[1] Emral, "Sepakbola Dasar," Padang; Sukabina Press, pp, 35-65. 2016.

[2] HPU, "Kurikulum Sepakbola Indonesia," Jakarta; PSSI. 2017.

[3] IFAB, "Law of The Game," Zurich; FIFA. 2017

[4] Davies, Jed, "The Philosophy of Football: In Shadows of Marcelo Bielsa," London; RocketBird Publishing. 2016 